\title{
Romantic Relationship Quality in the Digital Age: A Study with Young Adults
}

\author{
Virginia Sánchez ${ }^{1}$, Noelia Muñoz-Fernández ${ }^{1}$ and Rosario Ortega-Ruiz ${ }^{2}$ \\ 1 Universidad de Sevilla (Spain) \\ ${ }^{2}$ Universidad de Córdoba (Spain)
}

\begin{abstract}
Recent studies suggest that the online and offline behaviors young people display in romantic relationships are closely related. However, the differential effects of the dimensions of couple quality in the online context have not yet been explored in depth. The aim of this study was to explore online couple quality in young-adult relationships, and its association with romantic relationship satisfaction, also looking at effects of gender, age, and length of the relationship. 431 university students currently in a romantic relationship $(68.2 \%$ females; mean age $=21.57)$ participated in this study. They completed different self-report measures to tap the online quality of their romantic relationships (online intimacy, control, jealousy, intrusiveness, cyberdating practices, and communication strategies) and level of satisfaction with those relationships. Results showed that participants more often reported online intimacy $\left(M_{\text {men }}=2.49 ; M_{\text {women }}=2.38\right)$ than the negative scales of online quality (mean ranged from .43 to 1.50), and all the online quality scales decreased with age (correlations ranged from -.12 to -.30) and relationship length (correlations ranged from -.02 to -.20). Linear regression analyses indicated that online intimacy $(b=.32, p=.001)$ and intrusiveness $(b=.11, p=.035)$ were positively related to relationship satisfaction, while cyberdating practices $(b=-.20, p=.001)$ and communication strategies $(b=-.34, p=.001)$ were negatively correlated with relationship satisfaction. Moreover, gender and relationship length moderated some of these associations. Results indicate that while online quality and relationship satisfaction are related, the impact of different online quality dimensions on relationship satisfaction differs depending on a participant's sex, age, and relationship length.
\end{abstract}

Received 5 May 2016; Revised 24 March 2017; Accepted 27 March 2017

Keywords: communication, online couple quality, romantic relationships, satisfaction, young people.

There is no longer any doubt that Information and Communications Technology (ICT) is part of everyday life for young adults; they use it to communicate, and as a tool to learn and explore. Subrahmanyam and Šmahel (2011) proposed a theoretical model to analyze young people's online behavior from a psychodevelopmental perspective. According to those authors, ICT (understood as using mobile devices and social networking) has become a real space for young people's development and learning, a context in which they can express themselves and grapple with the main challenges of their age, which revolve around assuming responsibility in different spheres of social and personal life, including romantic life (Brown \& Bobkowski, 2011; Shulman \& Connolly, 2013). From that point of view, one would expect online and offline behavior to

Correspondence concerning this article should be addressed to Virginia Sánchez Jiménez. Departmento de Psicología Evolutiva y de la Educación. Universidad de Sevilla. C/ Camilo José Cela, s/n. 41018. Seville (Spain). Phone: +34-954557650. Fax: +34-954557650.

E-mail: virsan@us.es

This research was funded by the Spanish Ministerio de Economía y Competitividad into the national I+D program: (PSI2013-45118-R). Parejas y redes de iguales en la adolescencia. Noelia Muñoz-Fernández has a grant from the Spanish Ministerio de Educación, Cultura y Deporte (FPU2013/00830) be related, not only reflecting young people's interests and concerns, but providing two-way feedback.

Studies of online behavior in young adults seem to confirm Subrahmanyan and Šmahel's postulates (2011) that young adults use the Internet in fundamental ways to communicate with their romantic partner and develop the relationship (Fox \& Warber, 2013), and publicly share emotional states, photos, and other content from their romantic relationships (Carpenter \& Spottwood, 2013). By the same token, it has been suggested that online couple behavior influences perceptions of the romantic relationship overall. For example, Caughlin and Sharabi (2013) analyzed online and offline behavior in the form of private and public messages via Internet, text messages, chat, video chat, and phone calls between American young adults and their romantic partners. They concluded that people who adopted both modes of communication, in a balanced way, had more favorable results in terms of intimacy and relationship satisfaction than those who used only one (online or offline), and those who had trouble switching online to offline or vice versa. Similarly, Morey and her collaborators (Morey, Gentzler, Creasy, Oberhauser, \& Westerman, 2013) found that communicating via phone and text message was associated with greater relationship satisfaction and intimacy in American young adults. 
More numerous studies have analyzed the relation between negative online relationship dynamics and different indicators of romantic relationship quality in young adults. For instance, online jealousy - understood as an emotional reaction prompted by visualizing online relationship content - and concerns and suspicions about a partner's interest in someone else (Utz \& Beukeboom, 2011) have been associated with low levels of relationship satisfaction (Elphinston \& Noller, 2011), and predict involvement in psychological (Strawhun, Adams, \& Huss, 2013) and physical abuse (Sánchez, Muñoz, Nocentini, Ortega-Ruiz, \& Menesini, 2014). On the other hand, research on online intrusive behavior, which is understood as repeated, obsessive attempts to initiate contact and communicate with a partner after a break-up or fight, has revealed that people who exhibit these behaviors in online mode do so offline too (Spitzberg \& Hoobler, 2002; Strawhun et al., 2013), and has linked it to low relationship quality (Lavy, Mikulincer, Shaver, \& Gillath, 2009) as well as intimate partner abuse (Sánchez et al., 2014; Strawhun et al., 2013). Regarding online monitoring or control, that is, surveillance and tracking of the partner's online activity (Tokunaga, 2011), results have been inconclusive. Some studies have found negative associations between control and relationship satisfaction (Elphinston \& Noller, 2011), while other studies have not (Stewart, Dainton, \& Goodboy, 2014). Finally, the research on online infidelity, understood as using ICT to flirt or contact others, have produced similarly disparate results: some studies related it to lower relationship satisfaction (Cravens, Leckie, \& Whiting, 2013), while others found it was more closely tied to sensation-seeking behaviors than low relationship satisfaction (Hertlein \& Stevenson, 2010). What these studies do clearly suggest is that while positive online practices - like using ICT to communicate with one's partner, and spending time together online - are related to positive relationship outcomes, associations with negative online relationship dynamics have been inconclusive.

In addition to those findings, differences in online practices and relationship satisfaction have been observed as a function of sex, age, and relationship length. The research suggests that women are involved in longer, more serious relationships with higher satisfaction (Dhariwal, Connolly, Paciello, \& Caprara, 2009; Rauer, Pettit, Lansford, Bates, \& Dodge, 2013), but tend to exhibit more online jealousy (Muise, Christofides, \& Desmarais, 2014). Men, meanwhile, tend to engage in more cyberbullying and cyberdating (Duran-Segura \& Martínez-Pecino, 2015; Sánchez, Muñoz-Fernández, \& Ortega-Ruiz, 2015). To date, we do not know of previous studies that relate age to higher relationship satisfaction, but it does seem to be negatively associated with Internet usage (Correa, Hinsley, \& De Zuniga, 2010) and certain online practices, such as partner monitoring (Tokunaga, 2011). Studies exploring the effect of relationship length appear to be more conclusive, indicating that more enduring couples feel more satisfied with their relationships (Ahmetoglu, Swami, \& ChamorroPremuzic, 2010; Hurley \& Reese-Weber, 2012) and utilize the Internet less (Lenhart \& Duggan, 2014). Recently, Rahaman (2015) concluded that long-term couples presented less online conflicts, and therefore greater commitment to the relationship.

In light of the above, the literature suggests that the kind of relationship dynamics a couple establishes online impacts their satisfaction with the relationship; However, it could be hypothesized that this association can differ as a function of sex, age, and relationship length. The research to date on this association has focused on specific online behaviors - like jealousy, control, communication, and intrusiveness - only sometimes including the effects of variables like sex (Muise et al., 2014), age (Tokunaga, 2011), and relationship length (Rahaman, 2015). Thus, we do not know with certainty what dimensions of online couple quality are most important to explaining relationship satisfaction, nor what effect those three variables might have on the association.

In Spain, research on this subject remains nascent. Many studies have analyzed cyberbullying in young couples (Durán-Segura \& Martínez-Pecino, 2015) in relation to offline violence (Sánchez et al., 2014), but we know of no study that analyzed how online couple quality contributes to relationship satisfaction in a college population. In this study, we understand relationship satisfaction as an indicator of relationship quality, and as characterized by intimacy, communication, and a desire to stay in the relationship (Madsen \& Collins, 2011). With that in mind, this study's first objective is to analyze online relationship quality in young adult, Spanish couples, taking into account the effects of sex, age, and relationship duration. The second objective is to explore the connection between online relationship quality and relationship satisfaction, specifically analyzing which dimensions of online couple quality (intimacy, jealousy, control, intrusiveness, communication, or cyberdating practices) are most closely related to relationship satisfaction, and to include the possible effects of age, sex, and relationship length in the results.

According to earlier studies' findings, we expect that women will exhibit more online jealousy (Muise et al., 2014) and men more cyberdating (Sánchez et al., 2015), and that in general, positive and negative online practices will decrease with age (Tokunaga, 2011) and length of the relationship (Lenhart \& Duggan, 2014). Regarding the relationship between online couple quality and relationship satisfaction, we expect that positive dynamics like online intimacy will be positively 
associated with relationship satisfaction (Caughlin \& Sharabi, 2013; Morey et al., 2013). Since findings in Spain about negative online couple quality have been scant and inconclusive, we have formulated no clear hypothesis about it. It is for that reason that the second objective aims to further our understanding of this association by generating new data.

\section{Method}

\section{Participants}

Initially, 793 college students at the University of Córdoba (Spain) participated in this study. From those, 431 were selected because they reported a current dating relationship (68.2\% women; age range 18 to 26 years, average age $21.57, S D=1.92)$. Participants were selected through convenience sampling from the departments of Literature (10.8\%), Education (26\%), Law (3.9\%), Business Administration and Management (4.2\%), Occupational Science (11.4\%), Veterinary and Medicine $(19.3 \%)$, Biology (3.2\%), and Engineering (19.3\%), heeding Ferrer and collaborators' (2006) remarks about the impact of curriculum on romantic relationship knowledge (Ferrer, Bosh, Ramis, \& Navarro, 2006). The students' distribution by department was representative of the university sample at large.

The sample's characteristics and descriptive results appear in Table 1.

\section{Instruments}

\section{Ad hoc measures}

Participants were asked about descriptive variables including sex, age, family level of education, and hours of Internet use.

Table 1. Sample Descriptive Statistics

\begin{tabular}{clc}
\hline Sex & Men & $137(31.8 \%)$ \\
& Women & $294(68.2 \%)$ \\
Father's level of & None & $14(3.4 \%)$ \\
education & Elementary school & $188(45.3 \%)$ \\
& Secondary school & $110(26.6 \%)$ \\
& Higher education & $101(24.2 \%)$ \\
Mother's level & Other & $2(0.5 \%)$ \\
of education & None & $17(4 \%)$ \\
& Elementary school & $192(45.3 \%)$ \\
& Secondary school & $125(29.3 \%)$ \\
Relationship length & Higher education & $88(20.9 \%)$ \\
$(M ; S D)$ & Other & $2(0.5 \%)$ \\
Age $(M ; S D)$ & & $135.01(104.09)$ \\
\hline
\end{tabular}

Note: Father's level of education $(n=415)$; Mother's level of education $(n=424)$.

\section{Relationship status}

Two items from the Dating Questionnaire (Connolly, Craig, Goldberg, \& Pepler, 2004) were posed. The first gauges relationship status and was multiple-choice (response categories as follows: a) Yes, I have a girl(boy) friend right now; b) No, I don't have a girl(boy)friend right now, but I had one in the last two months; c) I don't have a girl(boy)friend right now, but I did more than two months ago; d) No, I've never had a girl(boy) friend). The second item measures relationship length in weeks. The relationship status variable was applied as a filter, such that only participants who reported a romantic relationship at the time they completed the questionnaire were selected for this study.

\section{Relationship satisfaction}

This was assessed using six items from the Network of Relationships Inventory (Furman \& Buhrmester, 1992), measured on a 5-point Likert scale with anchors 0 (never) and 4 (all the time) (e.g., "I am sure this relationship will continue in the future" "I tell my boy/girlfriend things I would not want others to know"). A given participant's relationship satisfaction score was computed from his or her average scores.

\section{Online couple quality}

This was measured by the Cyberdating Q_A (Sánchez et al., 2015). The questionnaire is comprised of 28 items on a 5-point Likert scale (from never-0 to always-4) that analyze six dimensions of online couple quality: (1) four items about online jealousy, which is a person's emotional reaction and concerns about content shared by their partner, and the possibility that he or she is interested in someone else (e.g., "I get jealous when my partner posts provocative photos on their social network profile;" "I worry about my partner starting a relationship with someone else via social networks"); (2) four items about online intrusive behavior, that is, trying to resume communication after an argument by means of mass, insistent messages and calls (e.g., "When we've had an argument and my partner blocks me, I use a friend's profile to leave him/her messages, communicate by chat or on their page;" "When we've had an argument and my partner blocks me, I use a friend's profile to leave him/her messages, communicate by chat or on their page"); (3) six items about online control, which is the process of supervising and monitoring the partner's profile and online activity in his or her social network (e.g., "I have added my partner's friends as a way of controlling him/her;" "I have opened a fake account so that my partner adds me and I can control him/her"); (4) three items about online intimacy, which refers to shared time on the Internet 
and a feeling of closeness to one's partner while online (e.g., "I have a really good time with my partner when we're online together;" "I spend a lot of free time talking to my partner on chat"); (5) four items about cyberdating practices, that is, contacting and flirting with other parties while in a relationship (e.g., "I have 'flirted' with other people via social networks whilst in a relationship;" "When I meet someone I like, I quickly give them my mobile number"); and (6) seven items referring to emotional communication strategies, which are tactics to manipulate or control one's partner, or display anger or show that there is a problem (e.g., "I use capital letters when I am annoyed with my partner;" "I use ellipses to insinuate something to my partner"). Scores on these online quality scales are calculated using participants' average scores. According to earlier results reported by the scale's authors, online intimacy is considered a positive dimension of online couple quality, and the remaining dimensions are negative.

\section{Procedure}

These self-report instruments were administered in paper form during school time in a single 40-minute session. Participants completed an informed consent form, and participation was entirely voluntary. Trained researchers executed data collection and we ensured the confidentiality of all information collected.

\section{Data analysis}

The first step was to do two Confirmatory Factor Analyses (CFAs) of online couple quality and relationship satisfaction in order to validate the instruments in this study's sample. Next, means comparisons were done as a function of gender, using Student's $t$ test on each scale of online couple quality and romantic relationship satisfaction. Subsequently, we analyzed Pearson's correlations between age, relationship duration, online couple quality, and relationship satisfaction. These analyses were done separately for men and women in order to differentially analyze the association between these variables by gender. To satisfy this study's second objective, a multiple linear regression was done using a step-wise method; in it, relationship satisfaction was the dependent variable, and sex, age, relationship length, and online couple quality were independent variables. Moderating variables (sex, age, and relationship length) were entered into a first block; a second block included the dimensions of online couple quality; and the third block added the interaction terms of the moderating variables in online couple quality: the interaction between sex and each dimension of online couple quality, the interaction between age and each dimension of online couple quality, and the interaction between relationship duration and each dimension of online couple quality. To diminish collinearity issues, all the independent variables were first standardized; all interactions were computed using standardized variables. The gender variable was coded such that a value of 0 was assigned to men, and 1 to women.

Analyses were conducted using the statistics packages Lisrel 8.72 and SPSS 23. Goodness of fit of the models resulting from CFA was appraised based on Satorra-Bentler's chi-square, RMSEA, and CFI. We determined that goodness of fit was adequate when the value of RMSEA was under .08, and CFI over .90.

\section{Results}

\section{Preliminary analyses}

Two CFAs were tested, one for online couple quality and another for romantic relationship satisfaction.

The model of online quality revealed a high correlation between online jealousy and online control $(r=.91)$, so we test a model with five correlated factors where those two scales merged into one factor. The remaining scales were the same as in the original instrument: online intrusiveness, online intimacy, cyberdating practices, and emotional communication strategies. The results of relationship satisfaction CFA, meanwhile, suggested freeing the correlations between error terms in three items (see Table 2). Both models showed goodness of fit.

\section{Descriptive analyses}

This study's first objective was to analyze online couple quality in romantic relationships between young adults as a function of sex, age, and relationship length. Table 3 presents means and standard deviations of online quality and relationship satisfaction as a function of sex. Evidently online intimacy, emotional communication strategies, and relationship satisfaction had the highest means, exceeding 3 points in young men and

Table 2. Goodness of Fit Indices for Online Couple Quality and Relationship Satisfaction

\begin{tabular}{lrrllll}
\hline & $\chi^{2} S-B$ & $d f$ & $p$ & RMSEA & CFI \\
\hline Online quality & 759.99 & 314 & $<.001$ & .06 & .94 \\
Relationship satisfaction* & 19.27 & 6 & $<.001$ & .08 & .99 \\
\hline
\end{tabular}

Note: Robust maximum likelihood estimation was employed because the assumption of multivariate normal distribution was not met. *Correlations between the error terms in three items were added; they measure relationship satisfaction. (Reliability: Online intimacy $\alpha=.68$; cyberdating practices $\alpha=.60$; online intrusiveness $\alpha=.65$; emotional communication strategies $\alpha=.76$; online jealousy-control $\alpha=.81$; romantic relationship satisfaction $\alpha=.87$.) 
Table 3. Comparison of Online Couple Quality and Relationship Satisfaction by Gender

\begin{tabular}{lccc}
\hline & Men & & Women \\
\cline { 2 - 2 } & Mean (SD) & & Mean (SD) \\
\hline Online intimacy & $2.49(.90)$ & $2.38(1.04)$ \\
Cyberdating practices & $.96(.72)^{* *}$ & $.71(.65)$ \\
Online jealousy/control & $.80(.58)$ & & $.84(.70)$ \\
Online intrusiveness & $.44(.58)$ & $.43(.59)$ \\
Emotional communication strategies & $1.43(.77)$ & $1.50(.86)$ \\
Relationship satisfaction & $3.29(.70)$ & $3.34(.71)$ \\
\hline
\end{tabular}

Note: ${ }^{*} p<.01 ; * p<.05$.

women alike. Online intrusiveness, conversely, had the lowest means. Significant differences were only found on the cyberdating practices dimension $(t(422)=3.552$; $p<.01, d=.35$ ), on which men scored higher than women on average, though the effect size was small.

Table 4 lists the correlations of age and relationship duration with online couple quality and relationship satisfaction, as a function of sex.

According to the results, age was negatively related to online intimacy, cyberdating practices, online jealousycontrol, and emotional communication strategies in men as well as women. Furthermore, it was not related to relationship satisfaction, but was related to relationship length in women. In terms of relationship duration, this was negatively associated with cyberdating practices in both sexes. In women only, we found that relationship length was negatively associated with online intimacy and emotional communication strategies. In men, no relationship was found between relationship duration and the other dimensions of online couple quality. All significant correlations registered a small or medium effect size.

\section{Regression model of the association between online couple quality and relationship satisfaction}

Table 5 presents results from the multiple linear regression model. As in the results in the last step, Model 7, we observed that relationship satisfaction was explained by relationship length, online intimacy, cyberdating practices, emotional communication strategies, online intrusiveness, the interaction between sex and communication strategies, and the interaction between relationship duration and cyberdating practices, with a total explained variance of $21.7 \%(F(7,400)=$ $15.810 ; p=.011$.

To be specific, relationship length, online intimacy, and online intrusiveness were observed to positively correlate with relationship satisfaction, whereas relationship satisfaction negatively correlated with cyberdating

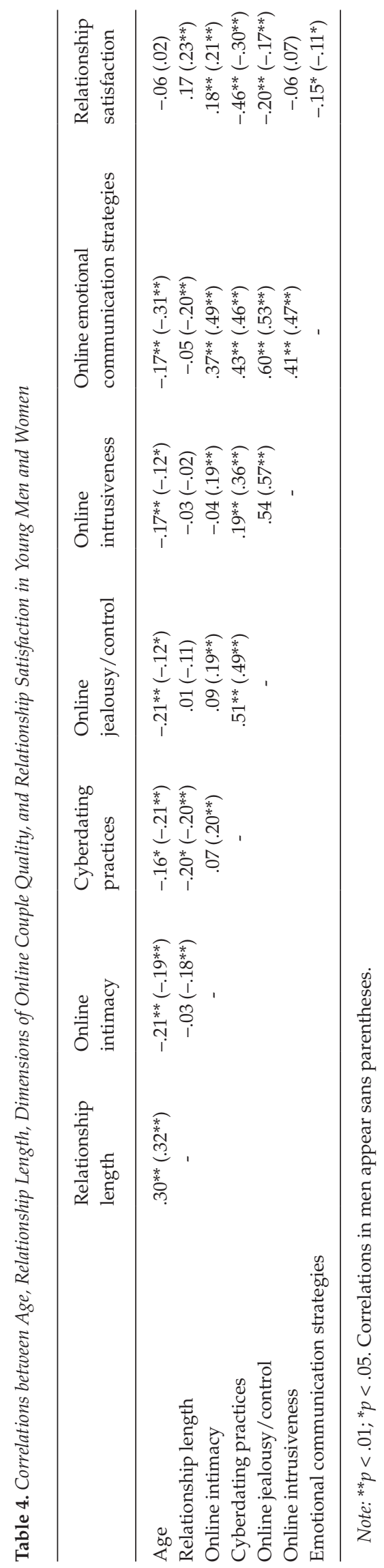


Table 5. Relationship Satisfaction Model Resulting from Hierarchical Multiple Linear Regression

\begin{tabular}{|c|c|c|c|c|c|c|}
\hline Models & & $B(S E)$ & $b$ & $C I$ & $t$ & $p$ \\
\hline Model $1\left(R^{2}=.048\right)$ & Relationship length & $.15(.03)$ & .22 & $(.09, .22)$ & 4.544 & .001 \\
\hline \multirow[t]{2}{*}{ Model $2\left(R^{2}=.114\right)$} & Relationship length & $.18(.03)$ & .25 & $(.11, .24)$ & 5.384 & .001 \\
\hline & Online intimacy & $.18(.03)$ & .26 & $(.12, .25)$ & 5.472 & .001 \\
\hline \multirow[t]{3}{*}{ Model $3\left(R^{2}=.170\right)$} & Relationship length & $.15(.03)$ & .21 & $(.08, .21)$ & 4.539 & .001 \\
\hline & Online intimacy & $.20(.03)$ & .29 & $(.14, .27)$ & 6.279 & .001 \\
\hline & Cyberdating practices & $-.17(.03)$ & -.25 & $(-.24,-.11)$ & -5.250 & .001 \\
\hline \multirow[t]{4}{*}{ Model $4\left(R^{2}=.180\right)$} & Relationship length & $.14(.03)$ & .21 & $(.08, .21)$ & 4.443 & .001 \\
\hline & Online intimacy & $.23(.04)$ & .33 & $(.16, .30)$ & 6.648 & .001 \\
\hline & Cyberdating practices & $-.15(.04)$ & -.21 & $(-.21,-.08)$ & -4.198 & .001 \\
\hline & Emotional communication strategies & $-.08(.04)$ & -.12 & $(-.16,-.01)$ & -2.155 & .032 \\
\hline \multirow[t]{5}{*}{ Model $5\left(\mathrm{R}^{2}=.189\right)$} & Relationship length & $.14(.03)$ & .20 & $(.08, .20)$ & 4.323 & .001 \\
\hline & Online intimacy & $.24(.04)$ & .34 & $(.17, .31)$ & 6.876 & .001 \\
\hline & Cyberdating practices & $-.15(.04)$ & -.22 & $(-.22,-.08)$ & -4.373 & .001 \\
\hline & Emotional communication strategies & $-.12(.04)$ & -.17 & $(-.20,-.04)$ & -2.888 & .004 \\
\hline & Online intrusiveness & $.08(.04)$ & .11 & $(-.01, .15)$ & 2.165 & .031 \\
\hline \multirow[t]{6}{*}{ Model $6\left(R^{2}=.205\right)$} & Relationship length & $.14(.03)$ & .21 & $(.08, .21)$ & 4.525 & .001 \\
\hline & Online intimacy & $.23(.04)$ & .33 & $(.16, .30)$ & 6.602 & .001 \\
\hline & Cyberdating practices & $-.16(.03)$ & -.23 & $(-.23,-.09)$ & -4.593 & .001 \\
\hline & Emotional communication strategies & $-.25(.06)$ & -.35 & $(-.36,-.13)$ & -4.065 & .001 \\
\hline & Online intrusiveness & $.08(.04)$ & .11 & $(.01, .15)$ & 2.166 & .031 \\
\hline & Sex*Emotional communication strategies & $.20(.07)$ & .23 & $(.06, .33)$ & 2.843 & .005 \\
\hline \multirow[t]{7}{*}{ Model $7\left(R^{2}=.216\right)$} & Relationship length & $.15(.03)$ & .22 & $(.09, .22)$ & 4.815 & .001 \\
\hline & Online intimacy & $.23(.04)$ & .32 & $(.16, .29)$ & 6.552 & .001 \\
\hline & Cyberdating practices & $-.14(.04)$ & -.20 & $(-.21,-.07)$ & -4.104 & .001 \\
\hline & Emotional communication strategies & $-.24(.06)$ & -.34 & $(-.35,-.12)$ & -3.936 & .001 \\
\hline & Online intrusiveness & $.07(.04)$ & .11 & $(.01, .14)$ & 2.115 & .035 \\
\hline & Sex*Emotional communication strategies & $.18(.07)$ & .21 & $(.05, .32)$ & 2.656 & .008 \\
\hline & Relationship length*Cyberdating P. & $.08(.03)$ & .11 & $(.01, .14)$ & 2.403 & .017 \\
\hline
\end{tabular}

practices and emotional communication strategies. Finally, to make the interaction terms easier to interpret, we carried out a simple analysis of slopes, finding that for the interaction between sex and communication strategies (Figure 1), the slope was significant in men only $(t=-3.795, p=.001$; for the women it was $t=-.435, p=.664)$ such that the more communication strategies male participants reported, the lower their satisfaction with the relationship.

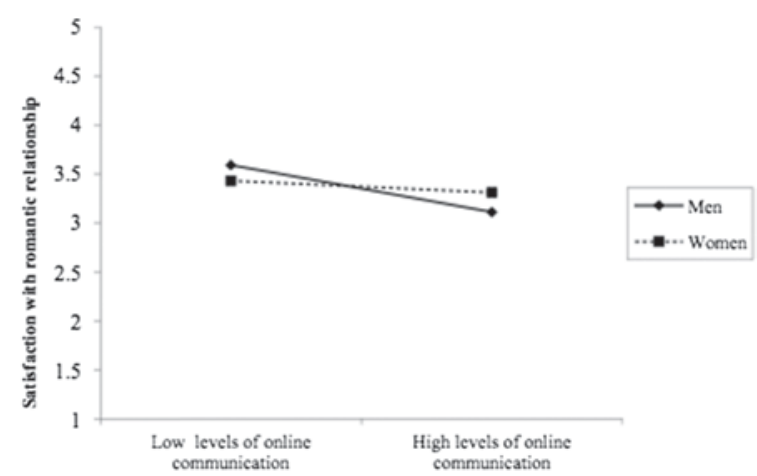

Figure 1. Interaction effect between sex and emotional online communication on relationship satisfaction.
On another note, regarding the interaction between cyberdating practices and relationship duration (Figure 2), the slope was only significant in shorterterm relationships $(t=-2.214, p=.027$; for longer relationships it was $t=-.717, p=.474)$. Accordingly, greater use of cyberdating practices was associated with lower relationship satisfaction in shorter relationships; that effect was not produced in longer relationships.

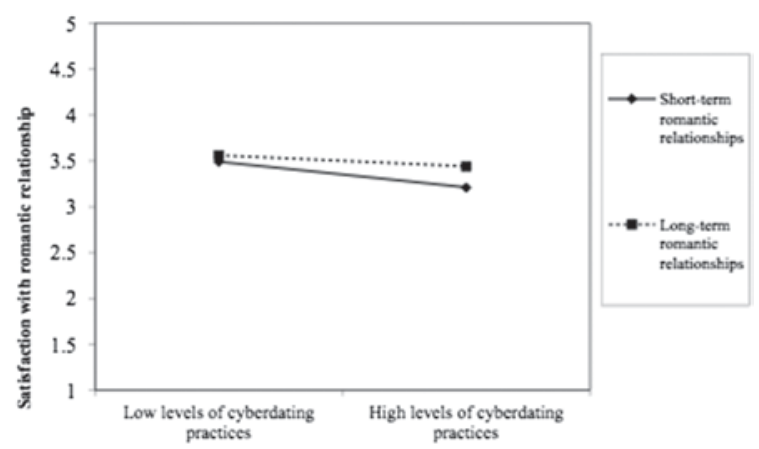

Figure 2. Interaction effect between relationship length and cyberdating practices on relationship satisfaction. 


\section{Discussion}

In recent years, we have seen a rising number of studies interested in how young people incorporate new technologies into their romantic relationships (Fox \& Warber, 2013; Morey et al., 2013; Stewart et al., 2014). However the influence of those behaviors on couples' lives is still up for debate, especially in Spain, where studies on this have been few. Therefore, this study aimed to explore relationship quality online in young adults, and its association with overall relationship satisfaction. In line with earlier studies that found differences on some measures of online couple quality as a function of sex (Muise et al., 2014), age (Tokunaga, 2011), or relationship length (Hurley \& Reese-Weber, 2012), this study also analyzed those three variables as potential moderators in the relationship between online quality and relationship satisfaction.

Descriptive analyses showed that these young people had moderate levels of online intimacy and communication strategies, and low online jealousy, intrusiveness, and control. These results confirm, first, that a couple's life also develops in the space of virtual media (Fox \& Warber, 2013), and second, that positive relationship dynamics are more common than negative, which is consistent with research examining relationship quality in couples off-line (Sánchez et al., 2014). Analysis of a potential gender effect on results revealed differences only in cyberdating practices, with young men more than women reporting that they flirt with various people while in a relationship, and emphasizing physique as the most important feature of people they meet on the Internet. These results are similar to findings in adolescent populations (Sánchez et al., 2015), which some authors have interpreted as a greater tendency for adolescent boys and young men to engage in sensation-seeking behaviors and risktaking (Hertlein \& Stevenson, 2010); that would logically increase in an environment where anonymity and privacy are attained more easily than off-line (Utz \& Beukeboom, 2011). Nonetheless, it might also reflect differing male and female interpretations of what they can and cannot do while in a relationship. Along those lines, studies about beliefs and attitudes about love have suggested that females still have more romantic, conservative ideas about love, while males more openly accept flirting and infidelity (Espinoza, Correa, \& García, 2014). The lack of differences on other scales, namely the negative ones, contradicts earlier findings that females exhibit higher levels of jealousy (Elphinston \& Noller, 2011), which would lead them to deploy more partner-monitoring and -control behaviors (Muise et al., 2014). These differences could be explained by methodological aspects such as different designs and measurement instruments. For example, Muise et al. (2014) used an experimental design to test whether jealousy levels predicted monitoring and surveillance behavior after seeing the partner's Facebook posts. In contrast, the present study was survey-based. In relation to measurements, in our study, jealousy and control dimensions were considered part of a single dimension; earlier studies examined them separately even though their authors concluded that the two scales are strongly correlated (Elphinston \& Noller, 2011; Muise et al., 2014). Future research could confirm whether the lack of differences between males and females on this dimension is due to methodology, or the presence of cultural differences, in love styles for instance (Rohman, Führer, \& Bierhoff, 2016).

Correlation analyses showed that age and relationship length were negatively associated with online couple quality scales, but that effect size was small. These results are in line with past studies where less partner monitoring was observed in older participants (Tokunaga, 2011); and more stable couples presented less flirting behavior and infidelity (Blow \& Harnett, 2005), as well as less use of new ICTs (Pew Research Centre, 2014). These results reinforce the hypothesis that the online world becomes less important in more stable couples during the transition to adulthood, a tendency that was not found, however, in adolescent populations (Sánchez et al., 2015). It is worth noting that the correlations were small, suggesting that while there was in fact a trend, these variables' association was not very strong. Future studies might extend participants' age range and test whether the online world's influence on the couple's life continues to decrease significantly in older participants.

Finally, multiple linear regression analysis showed that online quality was related to overall relationship satisfaction. In particular, satisfaction was explained positively by online intimacy and intrusiveness, and negatively by cyberdating and emotional communication strategies. These results confirm that the relationship dynamics unfolding in online media impact a young person's satisfaction with his or her partner, and highlight the connection between life on- and off-line (Subrahmanyan \& Šmahel, 2011). Accordingly, positive relationship dynamics that take place in online media, like spending time together on the Internet and having greater online intimacy, are associated with higher relationship satisfaction (Morey et al., 2013), while higher levels of cyberdating and emotional communication strategies were associated with lower relationship satisfaction. It is interesting to consider that online jealousy did not enter into our regression equation, in contrast to earlier studies on this subject (Elphinston \& Noller, 2011), and despite the association 
between the two variables found in correlation analyses, in females only. These results seem to indicate that even though the two variables are related, their influence on relationship satisfaction is not as important as other measures of online relationship quality. From that point of view, we believe that jointly analyzing the influence of different online quality scales on overall relationship satisfaction, as we did in this study, represents an advance over prior studies because it allowed for deeper analysis of how important each of the variables analyzed was.

Online intrusiveness was associated with higher relationship satisfaction, contradicting the findings of past studies relating it to negative relationship outcomes such as dating aggression (Sánchez et al., 2014). Some studies have tried to further explore the association between intrusiveness and relationship satisfaction by analyzing possible mediating variables, such as attachment styles. Lavy, Mikulincer, and Shaver (2013) found that intrusiveness was associated with higher relationship satisfaction in people with more insecure attachment styles, with intrusive behaviors lowering uncertainty (Stewart et al., 2014), which in turn increased perceived relationship satisfaction. Future research could confirm this meditational role of attachment style in the association, and the role of the other dyad member's reactions to such behaviors. We could hypothesize that one partner's type of response to an insecure and intrusive boy/girlfriend would reinforce his/her online behavior and thus increase his/ her relationship satisfaction.

The negative impact of cyberdating and emotional communication strategies on relationship satisfaction confirms others studies' findings about flirting and infidelity in virtual contexts (Cravens et al., 2013) and about the role of online conflict in relationship decline for both sexes (Clayton, 2014; Rahaman, 2015). These results were also moderated by gender and relationship length. Thus, while relationship length was associated with higher relationship satisfaction, it also moderated the association between cyberdating and satisfaction, such that cyberdating behaviors were associated with low relationship satisfaction in shorter relationships, but not in the context of longer relationships. These results are consistent with what Clayton, Nagurney, and Smith reported (2013); those authors suggested that flirting behavior and communication with ex-partners had a more negative impact on relationships less than three years than in more enduring couples. That would indicate that in less established couples - with less maturity, trust, and commitment - certain online behaviors (like the ones this study analyzed) negatively affect the relationship. In more stable, solid couples, meanwhile, those online behaviors are not important enough to significantly influence the overall value young people place on their dating relationships.

Gender ultimately moderated the negative relation between emotional communication strategies and relationship satisfaction such that men who make greater use of those strategies are less satisfied with their relationships. Given the nature of this scale, which taps communication strategies geared toward manipulating or controlling one's partner, or displaying anger when problems arise, these results suggest that when young men deploy these strategies, they are ineffective, which would explain their low levels of relationship satisfaction. Future studies could confirm this hypothesis and, using information from both members of the romantic dyad, determine how one partner using these communication strategies affects the couple's relationship dynamic, and therefore relationship satisfaction.

By way of summary, this study's results provide evidence that the online context matters to young adults in dating relationships, a connection which is moderated by sex and relationship length. We analyzed positive as well as negative relationship dynamics so we could take a closer look at the online dynamics that impact relationship satisfaction the most, in one of the first studies conducted in this area, especially in Spain.

This study was not, however, without various limitations that warrant consideration. The first is a matter of methodological design. This study's cross-sectional design makes it less possible to establish causal relations between variables; so future studies should utilize longitudinal designs to ascertain with greater accuracy the direction of the relationship among the study's variables. Next, the present study's accidental sampling method and sample size both limit the generalizability of results. Therefore we should broaden the study to include other Spanish universities using stratified random sampling. On another note, the very construct of online couple quality remains a challenge for the scientific community. Measures validated in different countries need to be developed in order to determine whether the differences observed might be due to cultural differences. Most studies have developed ad hoc measures of concrete negative behaviors like jealousy or controlling partner behavior, setting aside measures of positive online couple quality. Future studies should take a closer look at the range of positive behaviors couples can implement online, and how those impact relationship satisfaction. In closing, it is important for future studies to include perspective from both members of the couple, and different moderating variables - like attachment style and beliefs and attitudes about love - to better understand these variables' role in the association between life online and off. 


\section{References}

Ahmetoglu G., Swami V., \& Chamorro-Premuzic T. (2010). The relationship between dimensions of love, personality, and relationship length. Archives of Sexual Behavior, 39, 1181-1190. https://doi.org/10.1007/s10508-009-9515-5

Blow A. J., \& Hartnett K. (2005). Infidelity in committed relationships II: A substantive review. Journal of Marital and Family Therapy, 31, 217-233. https://doi.org/10.1111/ j.1752-0606.2005.tb01556.x

Brown J. D., \& Bobkowski P. S. (2011). Older and newer media: Patterns of use and effects on adolescents' health and well-being. Journal of Research on Adolescence, 21(1), 95-113. https://doi.org/10.1111/j.1532-7795.2010.00717.x

Carpenter C. J., \& Spottswood E. L. (2013). Exploring romantic relationships on social networking sites using the self-expansion model. Computers in Human Behavior, 29, 1531-1537. https://doi.org/10.1016/j.chb.2013.01.021

Caughlin J. P., \& Sharabi L. L. (2013). A communicative interdependence perspective of close relationships: The connections between mediated and unmediated interactions matter. Journal of Communication, 63, 873-893. https://doi.org/10.1111/jcom.12046

Clayton R. B. (2014). The third wheel: The impact of Twitter use on relationship infidelity and divorce. Cyberpsychology, Behavior, and Social Networking, 17, 425-430. https:/ / doi. org/10.1089/cyber.2013.0570

Clayton R. B., Nagurney A., \& Smith J. R. (2013). Cheating, breakup, and divorce: Is Facebook use to blame? Cyberpsychology, Behavior, and Social Networking, 16, 717-720. https:/ / doi.org/10.1089/cyber.2012.0424

Connolly J., Craig W., Goldberg A., \& Pepler D. (2004). Mixedgender groups, dating, and romantic relationships in early adolescence. Journal of Research on Adolescence, 14, 185-207.

Correa T., Hinsley A. W., \& Zuniga De, H. G. (2010). Who interacts on the Web?: The intersection of users' personality and social media use. Computers in Human Behavior, 26, 247-253. https: / / doi.org/10.1016/ j.chb.2009.09.003

Cravens J. D., Leckie K. R., \& Whiting J. B. (2013). Facebook infidelity: When poking becomes problematic. Contemporary Family Therapy, 35(1), 74-90. https:/ / doi. org/10.1007/s10591-012-9231-5

Dhariwal A., Connolly J., Paciello M., \& Caprara G. V. (2009). Adolescent peer relationships and emerging adult romantic styles: A longitudinal study of youth in an Italian community. Journal of Adolescent Research, 24, 579-600. https: / / doi.org/10.1177/0743558409341080

Durán-Segura M., \& Martínez-Pecino R. (2015). Ciberacoso mediante teléfono móvil e Internet en las relaciones de noviazgo entre jóvenes [Cyberharassment via cell phone and Internet in youth dating relationships]. Comunicar: Revista Científica de Comunicación y Educación, 22, 159-167. https://doi.org/10.3916/C44-2015-17

Elphinston R. A., \& Noller P. (2011). Time to face it! Facebook intrusion and the implications for romantic jealousy and relationship satisfaction. Cyberpsychology, Behavior, and Social Networking, 14, 631-635. https: / / doi. org/10.1089/cyber.2010.0318
Espinoza A. V., Correa F. E., \& García L. F. (2014). Percepción social de la infidelidad y estilos de amor en la pareja [Social perception of infidelity and love styles in relationships]. Enseñanza e Investigación en Psicología, 19(1), 135-147.

Ferrer V., Bosch E., Ramis M. C., \& Navarro C. (2006). Las creencias y actitudes sobre la violencia contra las mujeres en la pareja: Determinantes sociodemográficos, familiares $\mathrm{y}$ formativos [Beliefs and attitudes about intimate partner violence against women: Sociodemographic, family, and educational determinants]. Anales de Psicología, 22, 251-259.

Fox J., \& Warber K. M. (2013). Romantic relationship development in the age of Facebook: An exploratory study of emerging adults' perceptions, motives, and behaviors. Cyberpsychology, Behavior, and Social Networking, 16(1), 3-7. https://doi.org/10.1089/cyber.2012.0288

Furman W., \& Buhrmester D. (1992). Age and sex differences in perceptions of networks of personal relationships. Child Development, 63(1), 103-115. https://doi.org/10.2307/1130905

Hertlein K. M., \& Stevenson A. (2010). The seven "As" contributing to Internet-related intimacy problems. Cyberpsychology \& Behavior, 7, 207-230.

Hurley L., \& Reese-Weber M. (2012). Conflict strategies and intimacy: Variations by romantic relationship development and gender. Interpersona. An International Journal on Personal Relationships, 6, 200-210. https:/ /doi.org/10.5964/ ijpr.v6i2.101

Lavy S., Mikulincer M., \& Shaver P. R. (2013). Intrusiveness from an attachment theory perspective: A dyadic diary study. Personality and Individual Differences, 55, 972-977. https://doi.org/10.1016/j.paid.2013.08.006

Lavy S., Mikulincer M., Shaver P. R., \& Gillath O. (2009). Intrusiveness in romantic relationships: A cross-cultural perspective on imbalances between proximity and autonomy. Journal of Social and Personal Relationships, 26, 989-1008. https://doi.org/10.1177/ 0265407509347934

Lenhart A., \& Duggan M. (2014). Couples, the Internet, and social media: How American couples use digital technology to manage life, logistics, and emotional intimacy within their relationships. New York, NY: Pew Research Center. Retrieved from http://goo.gl/QYkcJv

Madsen S. D., \& Collins W. A. (2011). The salience of adolescent romantic experiences for romantic relationship qualities in young adulthood. Journal of Research on Adolescence, 21, 789-801. https://doi.org/10.1111/ j.1532-7795.2011.00737.x

Morey J. N., Gentzler A. L., Creasy B., Oberhauser A. M., \& Westerman D. (2013). Young adults' use of communication technology within their romantic relationships and associations with attachment style. Computers in Human Behavior, 29, 1771-1778. https://doi.org/10.1016/j.chb. 2013.02.019

Muise A., Christofides E., \& Desmarais S. (2014). "Creeping" or just information seeking? Gender differences in partner monitoring in response to jealousy on Facebook. Personal Relationships, 21(1), 35-50. https:/ / doi.org/10.1111/pere.12014 
Rahaman H. M. S. (2015). Romantic relationship length and its perceived quality: Mediating role of Facebook-related conflict. Europe's Journal of Psychology, 11, 395-405. https:/ / doi.org/10.5964/ejop.v11i3.932

Rauer A. J., Pettit G. S., Lansford J. E., Bates J. E., \& Dodge K. A. (2013). Romantic relationship patterns in young adulthood and their developmental antecedents. Developmental Psychology, 49, 2159-2171. https:/ / doi. org $/ 10.1037 / \mathrm{a} 0031845$

Rohman E., Führer A., \& Bierhoff H.-W. (2016). Relationship satisfaction across European cultures: The role of love styles. Cross-Cultural Research, 50, 178-211. https:/ / doi.org/10.1177/1069397116630950

Sánchez V., Muñoz N., Nocentini A., Ortega-Ruiz R., \& Menesini E. (2014). Online intrusiveness, online jealousy and dating aggression in young adults: A cross-national study (Spain-Italy). Maltrattamento e Abuso all'Infanzia, 3, 47-65. https: / / doi.org/10.3280/MAL2014-003004

Sánchez V., Muñoz-Fernández N., \& Ortega-Ruíz R. (2015). "Cyberdating Q_A": An instrument to assess the quality of adolescent dating relationships in social networks. Computers in Human Behavior, 48, 78-86. https://doi.org/ 10.1016/j.chb.2015.01.006

Shulman S., \& Connolly J. (2013). The challenge of romantic relationships in emerging adulthood: Reconceptualization of the field. Emerging Adulthood, 1(1), 27-39. https:/ / doi. org $/ 10.1177 / 2167696812467330$
Spitzberg B. H., \& Hoobler G. (2002). Cyberstalking and the technologies of interpersonal terrorism. New Media $\mathcal{E}$ Society, 4(1), 71-92. https://doi.org/10.1177/ 14614440222226271

Stewart M. C., Dainton M., \& Goodboy A. K. (2014). Maintaining relationships on Facebook: Associations with uncertainty, jealousy, and satisfaction. Communication Reports, 27(1), 13-26. https://doi.org/10.1080/08934215. 2013.845675

Strawhun J., Adams N., \& Huss M. T. (2013). The assessment of cyberstalking: An expanded examination including social networking, attachment, jealousy, and anger in relation to violence and abuse. Violence and Victims, 28, 715-730. https:/ / doi.org/10.1891/0886-6708. 11-00145

Subrahmanyam K., \& Šmahel D. (2011). Digital youth. New York, NY: Springer.

Tokunaga R. S. (2011). Social networking site or social surveillance site? Understanding the use of interpersonal electronic surveillance in romantic relationships. Computers in Human Behavior, 27, 705-713. https://doi.org/ 10.1016/j.chb.2010.08.014

Utz S., \& Beukeboom C. J. (2011). The role of social network sites in romantic relationships: Effects on jealousy and relationship happiness. Journal of Computer-Mediated Communication, 16, 511-527. https://doi.org/10.1111/ j.1083-6101.2011.01552.x 